\title{
ESPAÇOS LIVRES PÚBLICOS DA CIDADE DE ILHA SOLTEIRA, SP - BRAZIL
}

\section{URBAN OPEN SPACES FOR PUBLIC USE IN ILHA SOLTEIRA, SP - BRAZIL}

\section{Freitas-Lima, E. A. C. ${ }^{1}$ \& Cavalheiro, F.V. ${ }^{+}$}

${ }^{1}$ Departamento de Biologia, Faculdade de Engenharia de Ilha Solteira, UNESP, 15385 000, Ilha Solteira, São Paulo, Brasil.

\section{RESUMO}

O presente trabalho investigou os espaços livres públicos (ELP) da cidade de Ilha Solteira, SP. Os ELPs foram identificados e classificados em várias categorias. Foi também determinado o índice de espaços livres públicos (IELP) - relação entre o número de espaços livres públicos e o número de habitantes - para a cidade de Ilha Solteira. Finalmente foram propostas algumas estratégias de manejo dos ELPs, no contexto do planejamento urbano.

Palavras-chave: espaços livres públicos, paisagem urbana, áreas verdes.

\section{ABSTRACT}

The present paper aimed to study the urban open spaces for public use in Ilha Solteira, SP, Brazil. The urban open spaces were identified and classified into several categories. It was also determined the ratio between the urban open spaces for public use and the number of inhabitants of the city. Based on these parameters, some urban planning strategies for the management of the urban open spaces for public use were proposed.

Keywords: urban landscape, open spaces, public use 


\section{INTRODUÇÃO}

As cidades são constituídas por um mosaico de espaços, que podem ser diferenciados em construídos, livres de construções e espaços de integração viária (CAVALHEIRO \& DEL PICCHIA, 1992).

Os espaços livres de construções, quando permeáveis, apresentam uma série de funções ambientais, relacionadas com a qualidade ambiental urbana. Tais funções relacionam-se principalmente com a regulação do ciclo hidrológico, apresentando um papel importante na prevenção de enchentes urbanas. Muitos espaços livres de construções ou edificações, por outro lado, apresentam-se impermeabilizados, tais como algumas praças e estacionamentos, comprometendo sua função de conservação ambiental.

Quando os espaços livres de construções apresentam vegetação, os benefícios resultantes são consideravelmente maiores para a paisagem urbana. Algumas das principais funções desempenhadas pela vegetação urbana incluem: estabilidade microclimática; minimização da poluição atmosférica, por intermédio da biofiltração de gases poluentes e de sua ação como anteparo para deposição de material particulado; redução da poluição visual; redução da poluição sonora; melhoria da paisagem, por constituir-se em elemento especial de referência e estruturação do espaço; oferta e valorização de espaços de convívio social; valorização econômica das propriedades; e melhoria das condições de saúde física e mental da população (Bernatzky; Grey \& Denke; Jensen et alii; Lapoix; Polynton; Schubert apud MILANO, 1992).

A vegetação urbana apresenta também importante função na prevenção dos processos de erosão do solo e de deslizamentos de encostas. A retirada da vegetação associada com a impermeabilização do solo, altera o ciclo hidrológico urbano, levando ao acúmulo de água pluvial que é direcionada para locais nem sempre adequados, resultando em erosão do solo e assoreamento dos sistemas aquáticos a jusante (DETZEL, 1992).

Os espaços livres urbanos geralmente são considerados áreas verdes, quando apresentam-se predominantemente permeáveis e com significativa cobertura vegetal (MILANO,1988).

Algumas definições do termo área verde, entretanto, consideram o aspecto da acessibilidade ao público (NUCCI,1996). Desse modo áreas particulares ou o verde de acompanhamento viário, não seriam enquadradas na categoria de área verde.

A definição de sistema de espaços livres urbanos, segundo Llardent apud NUCCI (1996), o considera como um conjunto de espaços urbanos ao ar livre, destinados ao pedestre, para o descanso, a prática de esportes e à recreação. Observa-se nessa definição uma preocupação com a função de lazer ao ar livre desses espaços. Muitas vezes emprega-se o termo espaço aberto para caracterizar o acesso livre ao público 
LIMA et alii (1994) discutem a questão da terminologia empregada para designar os espaços livres urbanos, tais como áreas verdes, espaços abertos, arborização urbana, etc., com base em uma consulta realizada junto à comunidade científica. Foi observada uma grande variedade de termos para designar os diversos tipos de espaços, o que resulta numa certa confusão sobre qual o tipo de espaço que está sendo considerado, em cada caso.

Os espaços livres de construção, mas de uso particular, não cumprem a função social de oferta de lazer à população, uma vez que seu acesso é restrito. Apesar disso, apresentam uma função ecológica importante, no ambiente urbano, principalmente quando apresentam cobertura vegetal.

Existem ainda aqueles espaços livres públicos, com cobertura vegetal, mas que não se destinam à função de lazer, como os canteiros centrais de avenidas. Esse verde viário cumpre função ecológica no ambiente urbano, do mesmo modo que a arborização de ruas e os jardins particulares, mas não apresenta função de lazer para a população. Apesar de constituir-se num espaço de domínio público, o verde de acompanhamento viário não oferece as mínimas condições de segurança e adequação para cumprir a função de lazer.

As diferentes definições do termo área verde dificultam uma análise comparativa entre os índices de áreas verdes para as diferentes cidades. Dependendo da concepção do termo área verde, são computados nos índices de tais áreas, espaços públicos ou particulares, permeáveis ou não, unidades de conservação ambiental, verde de acompanhamento viário e, até mesmo, arborização de ruas.

A utilização diferenciada de indicadores dependentes e independentes da demografia, tais como índice de área verde por habitante e percentual de áreas verdes da área urbana, constitui-se numa alternativa para a dificuldade de estabelecer-se uma definição rígida para o termo área verde.

HENKE-OLIVEIRA (1996), por exemplo, utilizou o índice de áreas verdes por habitante (IAV), considerando apenas aquelas áreas de acesso livre ao público, que desempenhassem função recreativa, além das funções ecológicas e estéticas. $\mathrm{Na}$ determinação da porcentagem de áreas verdes da cidade (PAV), esse mesmo autor considerou a totalidade das áreas por ele definidas na categoria de área verde (incluindo verde viário e unidades de conservação).

Para assegurar o cumprimento satisfatório das funções ecológicas, sociais (lazer) e estéticas dos espaços livres urbanos, é necessário que esses sejam considerados como um sistema integrado, no processo de planejamento paisagístico (CAVALHEIRO \& DEL PICCHIA,1992). Cada tipo de espaço integrante do sistema apresenta 
características próprias, que lhes permitem desempenhar determinada função.

A classificação dos espaços livres urbanos representa uma etapa no contexto do processo de planejamento da paisagem urbana. De acordo com o sistema de classificação de RICHTER (1981) podem ser identificadas as seguintes categorias de espaços livres urbanos: jardim de representação, parque de vizinhança, parque de bairro, parque distrital, parque regional, verde de acompanhamento viário, unidades de conservação e áreas de uso especial (cemitérios, jardim botânico, jardim zoológico, etc.). Observa-se nesse modelo, uma regionalização das categorias de espaços livres, condicionando a distribuição espacial mais homogênea destas, o que permite a proporcionalidade entre os espaços livres e a população (MILANO, 1988).

No presente trabalho foi realizado um levantamento dos espaços livres públicos de Ilha Solteira, aqui considerados como aqueles espaços livres de construção, que apresentam acesso livre ao público e são destinados ao lazer ao ar livre.

\section{MATERIAL E MÉTODOS}

A área de estudo compreendeu a paisagem urbana de Ilha Solteira (Figura 1). O Município de Ilha Solteira teve sua origem como um núcleo urbano, construído com a finalidade de abrigar a mão de obra que iria trabalhar na construção da Usina de Ilha Solteira, sendo emancipado politicamente em 1993.

O município localiza-se na Região Noroeste do Estado de São Paulo, apresentando área de cerca de $647 \mathrm{Km}^{2}$, sendo $3 \%$ referentes à area urbana (FREITAS LIMA, 1997).

O estudo dos espaços livres públicos (ELP) envolveu uma avaliação qualitativa, em que cada espaço foi caracterizado, mediante o levantamento de campo e uma avaliação quantitativa. A determinação das áreas referentes a cada ELP identificado (avaliação quantitativa), foi realizada pelo levantamento de dados documentais. A tipologia dos espaços livres públicos foi baseada em RICHTER (1981). Utilizou-se a metodologia apresentada por CAVALHEIRO (1996) para a determinação do índice de espaços livres públicos (IELP).

\section{RESULTADOS E DISCUSSÃO}

Os espaços livres públicos representam aqueles livres de construção, localizados no núcleo urbano original, destinados ao lazer público para a população. Os espaços livres públicos potenciais representam aqueles espaços livres públicos, ainda não 
implantados, mas definidos nos projetos dos loteamentos novos (Jardim Aeroporto, Jardim Novo Horizonte e Recanto das Águas). Os espaços semi-públicos referem-se ao Estádio "Frei Arnaldo" e ao "Campo do Buru", ambos com acesso controlado.

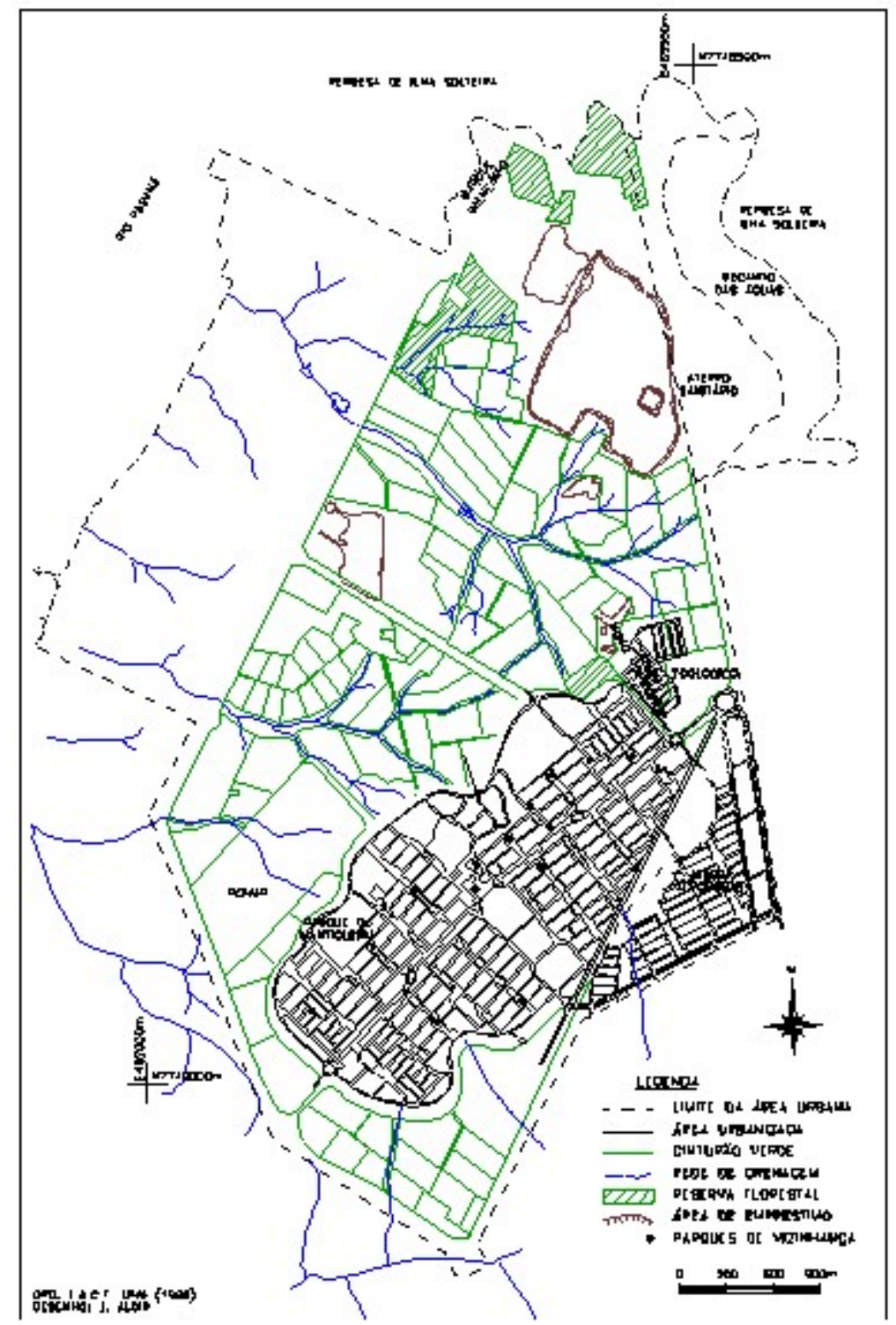

FIGURA 1 - Carta da área urbana de Ilha Solteira.

Na paisagem urbana de Ilha Solteira, foram identificados 19 espaços livres públicos, totalizando $472754,29 \mathrm{~m}^{2}$ de área. Nesse valor foi também incluído o Parque Zoológico de Ilha Solteira, de propriedade da CESP, parcialmente aberto ao público Não foram computados os espaços correspondentes aos jardins de representação, situados junto aos prédios públicos.

Do total de espaços identificados, nove corresponderam a praças públicas, que foram consideradas como parques de vizinhança; oito corresponderam a espaços públicos destinados ao lazer, mas com manejo paisagístico parcial, também incluídos na categoria parque de vizinhança; um correspondeu a um parque de bairro (Parque da Mantiqueira); um foi correspondente a um parque distrital (Parque Balneário) e um ao 
Zoológico (Tabela 1, Figura 1).

Dois espaços livres de construção, o Estádio "Municipal "Frei Arnaldo" e o "Campo do Buru", foram incluídos na categoria de espaços semi-públicos. Ambos são de propriedade da Prefeitura Municipal de Ilha Solteira, sendo disponíveis ao uso da população, de forma controlada.

Existem, ainda, as áreas consideradas como recantos e jardins que não foram computadas no cálculo de espaços livres públicos, uma vez que não se dispunha dos valores referentes às suas respectivas áreas. Algumas dessas áreas apresentam-se arborizadas. Observa-se, desse modo, que existe um potencial para criação de novos espaços livres públicos, não passível de ser computado com a metodologia aqui utilizada.

Os espaços livres públicos identificados como tal nos projetos dos loteamentos Jardim Novo Horizonte, Jardim Aeroporto, Recanto das Águas e Quadra AM-13, não foram computados nos cálculos efetuados, por ainda não terem sido implantados de fato. O conjunto desses espaços, considerados como espaços livres públicos potenciais (ELPP) totaliza $373905,97 \mathrm{~m}^{2}$, com porcentagens variando de $11,82 \%$ a $29,35 \%$ da área total do loteamento.

Tabela 1 - Categorias e áreas respectivas dos espaços livres públicos na paisagem urbana de Ilha Solteira, em 1997.

\begin{tabular}{||l||c|c||}
\hline \multicolumn{1}{|c||}{$\begin{array}{c}\text { Categoria de espaço } \\
\text { público }\end{array}$} & Área $\left(\mathrm{m}^{2}\right)$ & $\%$ \\
\hline \hline $\begin{array}{l}\text { Parques de vizinhança - } \\
\text { praças }\end{array}$ & 25383,26 & 5,37 \\
\hline $\begin{array}{l}\text { Parques de vizinhança - } \\
\text { outros* }\end{array}$ & 34921,22 & 7,39 \\
\hline $\begin{array}{l}\text { Parque de bairro - P } \\
\text { Mantiqueira }\end{array}$ & 115921,81 & 24,52 \\
\hline \hline $\begin{array}{l}\text { Parque distrital - P. } \\
\text { Balneário }\end{array}$ & 121700,00 & 25,74 \\
\hline \hline $\begin{array}{l}\text { Área de uso espec. - } \\
\text { Zoológico }\end{array}$ & 174828,00 & 36,98 \\
\hline \hline Total & 472754,29 & 100,00 \\
\hline \hline
\end{tabular}

* ELP caracterizados por apresentar manejo paisagístico parcial. 
Além dos aspectos quantitativos, a qualidade e a distribuição dos espaços livres públicos na malha urbana devem ser considerados na avaliação da paisagem urbana.

Os parques de vizinhança encontram-se relativamente bem distribuídos espacialmente na paisagem urbana. Observa-se uma certa deficiência dessa categoria de espaços na porção nordeste do núcleo urbano, devido às mudanças ocorridas no projeto original do núcleo urbano (Figura 1).

A análise da estruturação física dos espaços representados pelas praças públicas de Ilha Solteira, revela que nenhuma delas oferece equipamentos recreativos, estando mais destinadas a constituírem-se em locais de encontro ou passagem da população (Figura 2).

Com relação à categoria parque de bairro, observa-se que a cidade conta apenas com o Parque da Mantiqueira, o qual encontra-se em condições precárias, inclusive com alguns brinquedos quebrados (Figura 3).

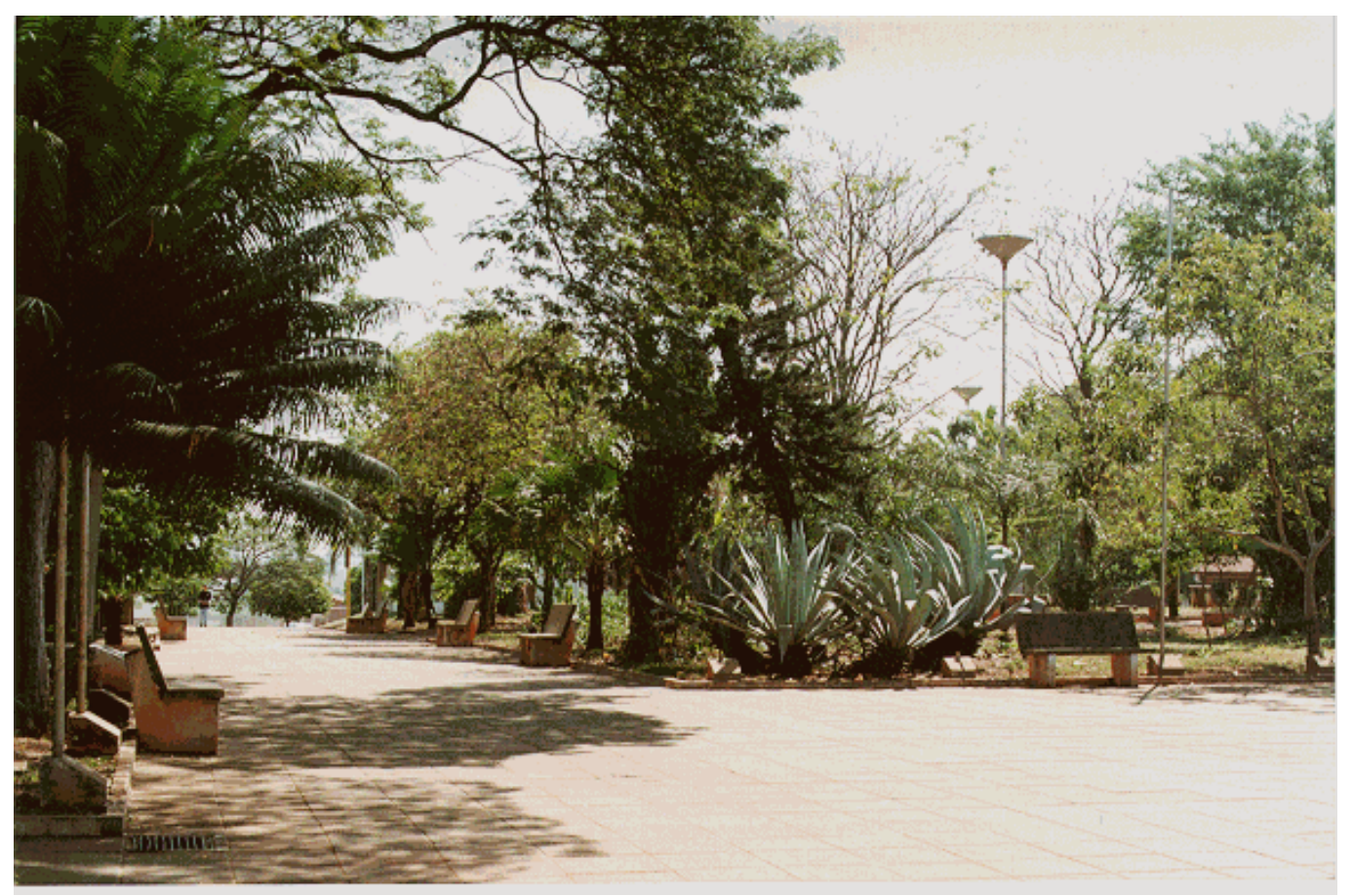

Figura 2 - Vista da Praça da Integração. Foto: Valdeir Rodrigues (1997). 


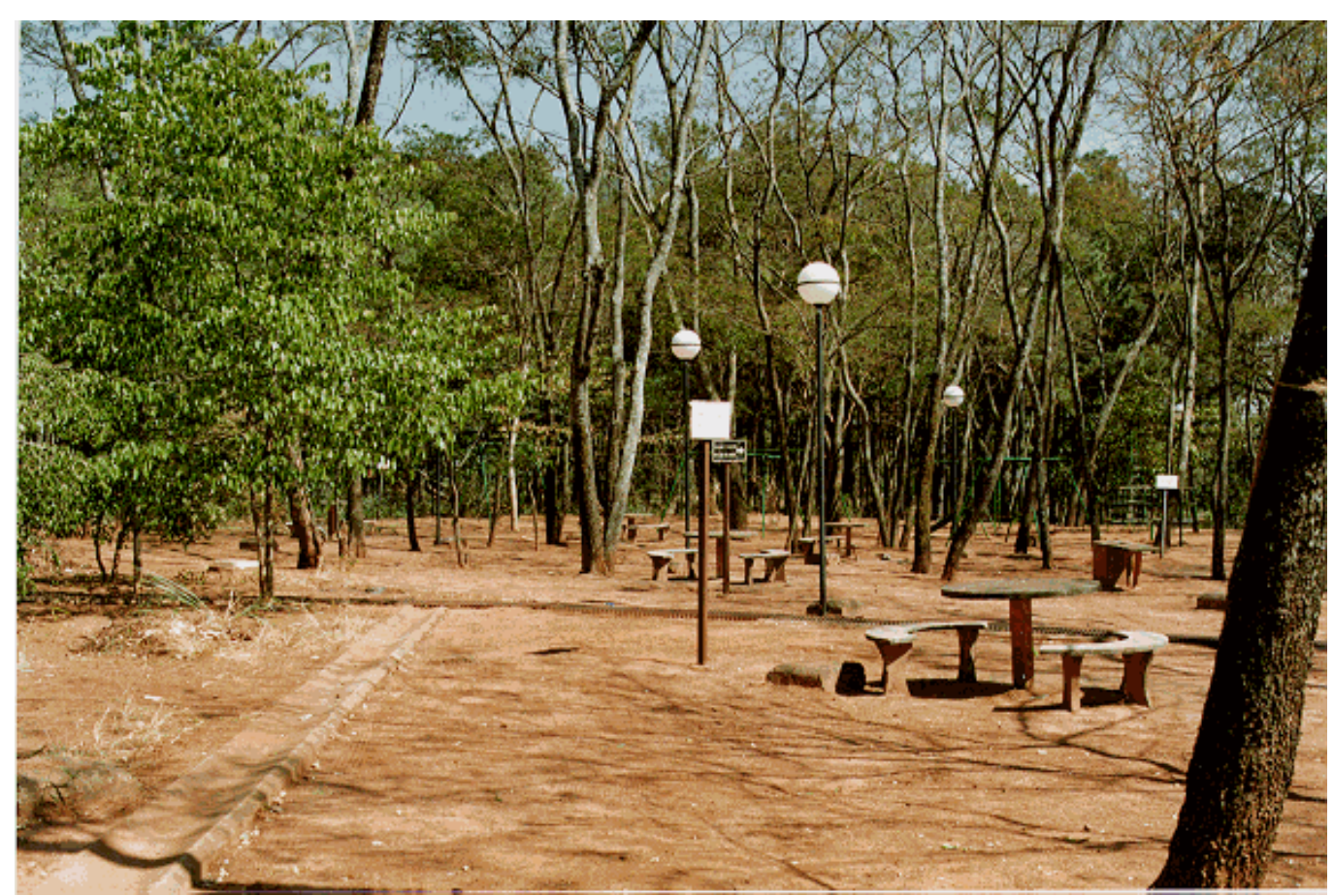

Figura 3 - Vista interna do P. Mantiqueira. Foto: Valdeir Rodrigues (1997).

O Zoológico de Ilha Solteira, incluído na categoria de Área de Uso Especial, apesar de ser uma propriedade particular (CESP), cumpre uma importante função de lazer e de educação ambiental na cidade de Ilha Solteira, abrindo regularmente ao público nos finais de semana (Figura 4).

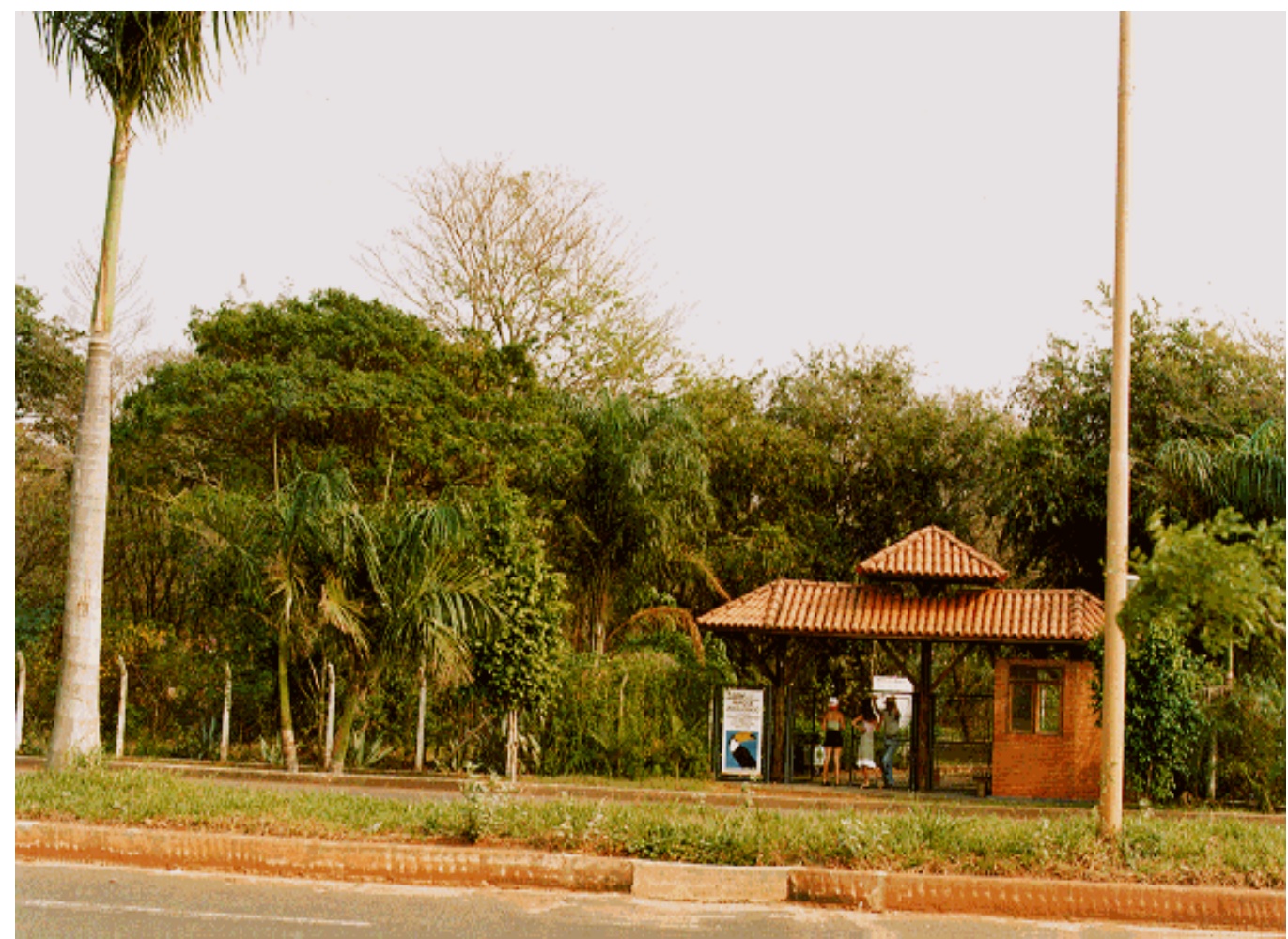

Figura 4 - Vista do Zoológico de Ilha Solteira. Foto: Valdeir Rodrigues (1997). 
O Parque Balneário foi enquadrado na categoria de parque distrital ou da cidade, por apresentar mais de 100 ha de área e atrair pessoas de toda a área urbana, de acordo com critérios apresentados em CAVALHEIRO e DEL PICCHIA (1992). Localmente conhecido como "Prainha", esse parque contém equipamentos recreativos infantis, um calçadão, um restaurante, bares, quiosques, além de áreas para acampamento (Figura 5).

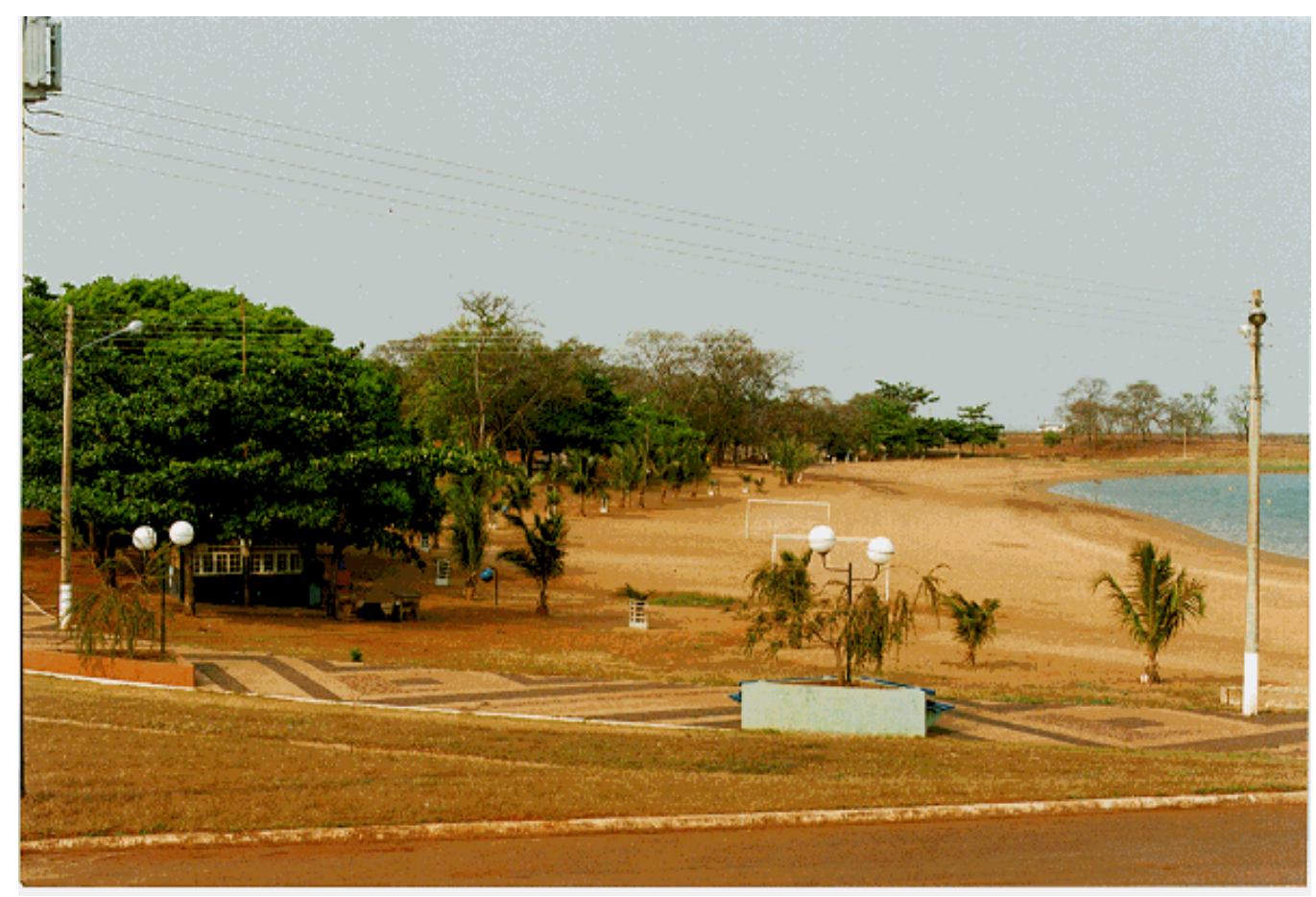

Figura 5 - Vista do Parque Balneário. Foto: Valdeir Rodrigues (1997).

Uma maneira de representar-se a expressividade dos espaços livres públicos numa cidade é mediante a relação entre área e habitantes. $\mathrm{Na}$ área urbana de Ilha Solteira, concentra-se 96\% (21269 habitantes) da população do município (22149 habitantes), de acordo com os dados da FIBGE, para o ano de 1996. Considerando-se os dados computados no presente trabalho, a cidade de Ilha Solteira apresenta uma relação de $22,23 \mathrm{~m}^{2}$ de espaços livres públicos por habitante.

Questionar se esses índices podem ser considerados adequados ou não, é uma questão bastante complexa, devido a falta de um critério amplamente aceito pela comunidade científica. A literatura científica ou não costuma citar o índice de $12 \mathrm{~m}^{2}$ de áreas verdes por habitante como sendo recomendado pela ONU, OMS ou FAO. CAVALHEIRO \& DEL PICCHIA (1992) afirmam, entretanto, que em consultas realizadas a esses órgãos foi constatado o não conhecimento a respeito do referido índice, por tais instituições. Os autores concluem, com base em revisões bibliográficas, que tal 
índice possa estar sendo referido tão somente às necessidades de parques de bairro e parques distritais que somam de $12 \mathrm{~m}^{2}$ a $13 \mathrm{~m}^{2}$ por habitante, segundo, por exemplo, sugestão da "Conferência Permanente dos Diretores de Parques e Jardins da República Federal da Alemanha".

Considerando-se apenas as categorias de parque de bairro e distrital, em Ilha Solteira, o IELP equivale a $11,17 \mathrm{~m}^{2}$ por habitante (Tabela 2).

Tabela 2 - Índice de espaços livres públicos por habitantes (IELP), segundo diferentes categorias, na cidade de Ilha Solteira, em 1997.

\begin{tabular}{||l||c||}
\hline \multicolumn{1}{|c|}{ Categorias de ELP } & IELP $\left(\mathrm{m}^{2} / \mathrm{hab}\right)$ \\
\hline \hline Parques de vizinhança & 2.84 \\
\hline \hline Parques de bairro & 5,45 \\
\hline \hline Parque distrital & 5,72 \\
\hline \hline $\begin{array}{l}\text { Área de uso especial (P. } \\
\text { Zoológico) }\end{array}$ & 8,22 \\
\hline \hline Total & 22,23 \\
\hline
\end{tabular}

De acordo com Llardent apud NUCCI (1996) as cidades deveriam contar com $35 \mathrm{~m}^{2}$ de espaços livres públicos por habitantes, distribuídos em $17,5 \mathrm{~m}^{2} / \mathrm{hab}$ para a trama verde de detalhe dos conjuntos habitacionais (até $1000 \mathrm{~m}$ distantes das residências) e $17,5 \mathrm{~m}^{2} /$ hab para a trama verde básica (escala da cidade).

Considerando-se a escala da cidade observa-se que Ilha Solteira apresenta um IELP de 19,39 $\mathrm{m}^{2} /$ hab. Com relação aos parques de vizinhança, ou seja, na escala dos conjuntos residenciais, o IELP corresponde a apenas $2,84 \mathrm{~m}^{2} / \mathrm{hab}$.

Jambor \& Szilagyi apud NUCCI (1996) sugerem valores que variam de 21 $\mathrm{m}^{2} /$ hab a $30 \mathrm{~m}^{2} /$ hab como índices de espaços livres públicos. A Associação Nacional de Recreação dos EUA no Congresso Internacional de Recreação (1956, Filadélfia) sugeriu como valores recomendados para áreas verdes entre $28 \mathrm{~m}^{2} / \mathrm{hab}$ e $40 \mathrm{~m}^{2} / \mathrm{hab}$ (MILANO, 1992). No Brasil, a Sociedade Brasileira de Arborização Urbana (SBAU) sugeriu um índice de $15 \mathrm{~m}^{2}$ /hab para áreas verdes públicas (NUCCI, 1996). 
A comparação entre os IELP referentes às diversas cidades brasileiras tornase bastante difícil devido aos procedimentos diversos empregados para sua determinação. Em alguns casos são computados espaços como o verde de acompanhamento viário, unidades de conservação, arborização de ruas, etc. para a obtenção da relação entre espaços livres e habitantes.

O IELP encontrado para Ilha Solteira apresenta-se satisfatório, quando comparado com aqueles citados como adequados segundo algumas fontes bibliográficas, considerando-se a escala da cidade. Com relação à escala dos conjuntos residenciais, entretanto, observa-se um IELP insatisfatório . Deve ser ainda ressaltado que o IELP obtido no presente trabalho, poderia estar subestimado por não considerar os jardins de representação, bem como os "recantos e jardins". Além disso, a implantação dos espaços potenciais situados nos loteamentos novos, elevaria o IELP da cidade para $39,81 \mathrm{~m}^{2} / \mathrm{hab}$. Por outro lado, os espaços aqui identificados como recebendo um manejo paisagístico parcial foram computados para a determinação do IELP, apesar de poderem ser considerados, dependendo do critério adotado, como espaços potenciais, em função de sua situação atual de manejo. Se tais espaços fossem excluídos dos cálculos, o IELP de Ilha Solteira seria equivalente a $20,59 \mathrm{~m}^{2} / \mathrm{hab}$.

Com relação à função ecológica das áreas verdes, a relação entre cobertura vegetal e área urbana parece mais apropriada do que a relação entre área verde e número de habitantes. A cobertura vegetal de uma cidade inclui áreas públicas e privadas, que podem estar enquadradas nas diversas categorias de usos do solo urbano (residencial, industrial, conservação, lazer, etc.). Ou seja, os ELPs não são os únicos responsáveis pela manutenção da cobertura vegetal, na paisagem urbana.

O IELP é mais indicado para a avaliação da função social (lazer) dos espaços livres. A utilização do índice como expressão da relação entre área de espaços livres públicos e habitantes, ao invés de um índice de áreas verdes por habitante, parece mais satisfatória na avaliação da função social dos ELP, uma vez que nem todo ELP constituise numa área verde.

A recomendação de Llardent apud NUCCI (1996), de IELPs distribuídos em $17,5 \mathrm{~m}^{2} /$ hab para a escala dos conjuntos residenciais e $17,5 \mathrm{~m}^{2} / \mathrm{hab}$ para a escala da cidade, permite uma maior flexibilização no processo de planejamento do sistema de espaços livres urbanos. O poder público pode determinar, mediante legislação municipal de parcelamento do solo, valores mínimos de espaços livres públicos para cada loteamento.

Considerando-se apenas a legislação federal (Lei Lehman) é exigido para a aprovação do loteamento um mínimo de $35 \%$ de áreas públicas, incluindo o sistema viário e as áreas para instalação de equipamentos comunitários (hospitais, escolas, etc.). É 
necessário que seja definido na legislação municipal o percentual específico para espaços livres públicos. Considerando-se a escala de um loteamento urbano, o valor em torno de $17,5 \mathrm{~m}^{2} / \mathrm{hab}$ seria recomendado, a fim de suprir as necessidades de oferta de espaços destinados ao lazer ao ar livre e com acesso livre pela população. A oferta de ELP, considerando-se a escala da cidade, poderia ser suprida pelo planejamento de parques de bairro e da cidade. Para tal é extremamente importante que o poder público municipal disponha de um estoque de áreas públicas.

Com base nos resultados obtidos no presente trabalho foram propostas algumas estratégias para o manejo dos espaços livres públicos. Tais estratégias apresentaram como princípios norteadores, a consideração dos espaços livres urbanos como valores sociais, importantes para uma melhoria da qualidade de vida. A primeira estratégia refere-se à implantação de todos os espaços livres públicos potenciais, bem como, providenciar o tratamento paisagístico adequado, àqueles espaços parcialmente manejados.

A segunda estratégia diz respeito ao aumento da oferta de espaços livres públicos, mediante o aproveitamento de uma grande área de empréstimo, localizada próximo ao atual aterro sanitário. Nessa área poderia ser implantado um parque de recreação, ao qual num futuro próximo poderia ser anexada a área do aterro sanitário, após seu esgotamento. Essa proposta já foi apresentada no relatório do CEPAM (1989), quando da realização de um estudo sobre as possibilidades de desenvolvimento econômico de Ilha Solteira. Nesse mesmo relatório é enfatizada a adequação do município para as atividades turísticas, devido à presença da Represa de Ilha Solteira. Uma oferta maior de espaços de recreação seria mais um atrativo para o desenvolvimento do turismo local.

A terceira estratégia visa aumentar a cobertura vegetal da área urbana, principalmente nos loteamentos residenciais, por meio da arborização de ruas e dos espaços livres públicos. A meta seria transformar todos espaços livres públicos em áreas verdes, interligadas por meio da arborização de ruas. Para o sucesso dessa estratégia, seria recomendável a realização de um plano diretor de arborização urbana, o qual poderia ser realizado simultaneamente ao plano diretor urbano.

\section{CONCLUSÕES}

A comparação entre os vários índices utilizados no estudo de áreas verdes urbanas permitiu concluir que:

1. Os vários índices que expressam as relações entre espaços urbanos e população devem ser interpretados com cautela, de acordo com o objetivo que suscita a análise da 
paisagem. A relação entre os espaços livres de construção e a área urbana total, propicia uma importante informação sobre a qualidade da paisagem, em termos de permeabilidade do solo. Do mesmo modo, a relação entre áreas verdes e área urbana total, também diz respeito à função ecológica das áreas verdes.(espaços livres de construção com cobertura vegetal). Por outro lado, o índice de espaços livres públicos é mais indicado para a avaliação da função social (lazer) dos espaços livres urbanos, uma vez que considera apenas aqueles espaços públicos, ou seja, com acesso garantido à população.

2. Considerando-se a paisagem urbana de Ilha Solteira, a proporção de espaços livres de construção é representativa, devido à presença do Cinturão Verde, de uso agrário, localizado no perímetro urbano. Contudo, na paisagem do núcleo urbano de Ilha Solteira, existe uma pequena proporção de espaços livres urbanos.

3. A análise do índice de espaços livres públicos determinado para Ilha Solteira no presente trabalho revela a necessidade de aumentar a oferta de tais espaços à população, principalmente considerando-se a categoria parques de vizinhança. Ao mesmo tempo, é extremamente necessário que seja feito o tratamento paisagístico adequado dos espaços livres públicos.

\section{REFERÊNCIAS}

BUENOS AIRES. Subsecretaria de Ordenamiento Ambiental. Los espacios abiertos metropolitanos. 1980. (Separata especial do número 19 da revista "ambiente", abril 1980).

CAVAlHEIRO, F. \& DEL PICCHIA, P. C. D. Áreas verdes: conceitos, objetivos e diretrizes para o planejamento. In: CONGRESSO BRASILEIRO DE ARBORIZAÇÃO URBANA, 1, 1992, Vitória. Anais... Vitória, 1992. p.29-38.

CAVALHEIRO,F. Metodologia para determinação do índice de espaços livres. In: CONGRESSO BRASILEIRO DE ARBORIZAÇÃO URBANA, 3. 1996. Anais...(no prelo).

CEPAM - CENTRO DE ESTUDOS E PESQUISAS DE ADMINISTRAÇÃO MUNICIPAL. Projeto Ilha Solteira: Alternativas para o desenvolvimento econômico local e elaboração de legislação de parcelamento, uso e ocupação do solo. São Paulo: CEPAM. 1989. v6. 109p.

DETZEL, V. A. Arborização urbana: importância e avaliação econômica. In: CONGRESSO BRASILEIRO DE ARBORIZAÇÃO URBANA, 1, 1992. Anais... Vitória: Sociedade Brasileira de Arborização Urbana, 1992. p.39-52. 
FREITAS LIMA,E.AC. Estudo da paisagem do Município de Ilha Solteira-SP: subsídios para o planejamento físico-ambiental. São Carlos, 1997. 120p. Tese (Doutorado em Ecologia) - Universidade Federal de São Carlos.

HENKE-OLIVEIRA, C. Planejamento ambiental na cidade de São Carlos com ênfase nas áreas públicas e áreas verdes: diagnóstico e propostas. São Carlos. 1996. 234p. Dissertação (Mestrado em Ecologia) - Universidade Federal de São Carlos.

LIMA, A. M. L. P. et alii. Problemas de utilização na conceituação de termos como espaços livres, áreas verdes e correlatos. In: CONGRESSO BRASILEIRO DE ARBORIZAÇÃO URBANA, 2, 1994. São Luís. Anais... São Luís, 1994. p. 539-549.

MILANO, M. S. Avaliação quali-quantitativa e manejo da arborização urbana: exemplo de Maringá - PR. Curitiba. 1988. 120p. Tese (Doutorado em Engenharia Florestal). Universidade Federal do Paraná.

MILANO, M. S. A cidade, os espaços abertos e a vegetação. In: CONGRESSO BRASILEIRO DE ARBORIZAÇÃO URBANA, 1, 1992, Vitória. Anais...Vitória, 1992. p3 -14.

NUCCI, J. C. Qualidade ambiental e adensamento: um estudo de planejamento da paisagem no distrito de Santa Cecília MSP). São Paulo. 1996. 229p. Tese (Doutorado em Geografia Física) - Faculdade de Filosofia, Letras e Ciências Humanas, Universidade de São Paulo.

RICHTER, G. Handbuch stadtgrun. Munique: B.L.V., 1981. P.33-76. 